\title{
Primary Exploration on New Chinese Architecture Design Strategy in Ecological Civilization Perspective
}

\author{
LIANG Jun \\ Art and Design Institute of Nanchang Hangkou University, China \\ liangjun239@sina.com
}

\begin{abstract}
Keywords: Ecological civilization; New Chinese architecture; Design strategy; Culture
Abstract. The concept of new Chinese architecture has new interpretation in ecological civilization era. It not only should be rooted in current society culture and traced in historical tradition, but also should be faced to new era of harmonious coexistence between human beings and nature. In the paper, the cultural background of new Chinese architectural design is revealed under the perspective of ecological ethics. The basic concepts thereof are described. The designed basic principles are summarized.
\end{abstract}

\section{Introduction}

Changes in architectural style are always rooted in the development evolution of the culture thereof. A functionalism standpoint is adopted in modernism architecture. An internationalized and standardized form language is pursued for solving the problem of large batch of architectures which were urgent at the beginning of last century initially. The first world culture convergence is responded. In postmodern context, people are not willing to endure form monotony and emotional indifference of modernist architecture with the improvement of life quality. They begin to pay close attention to personality and pursue more life details. Significance and value are discovered in tradition, and identity is discovered. Therefore, a regional and national new Chinese architecture style is also produced in China. However, a protective concept with emphasis on harmonious coexistence among human beings and between human beings and nature begins to enjoy popular support currently with the rise of global ecological civilization. Chinese regional architecture also should be included in new perspective of ecological ethics. Its cultural background, design idea, method and strategy should be considered again. New levels of value and contents are given to the architecture.

\section{Research on cultural background of new Chinese architecture}

New Chinese architecture should embody a changing new culture in China contemporarily under the ecological perspective. It is integrated with the factor of ecological civilization. Essence of ancient Chinese traditional culture is also inherited. All culture achievements due to collision and exchange of human civilization are absorbed, including contribution of western modern and postmodern thoughts.

\section{New Chinese architecture and ecological civilization}

Ecological civilization has the core concept of harmony. Transformation of value concepts is also realized in new Chinese architectural design under the ecological perspective. Firstly, the value of prevailing anthropocentrism should be changed. Novel value concept of harmonious coexistence between human beings and non-human species should be established. Since all lives belong to natural network, human beings and everything in the world belong to communities with a common future. The most humble life has own value and significance in ecological net. It is required that design and creation of new Chinese architecture should meet demand of human beings on one hand, survival rights of other species also should be considered on the other hand. Secondly, design guidance of new Chinese architecture should be converted from competitive pursuit on material desire to realization of actual freedom for human beings, namely humanity freedom which is not driven and enslaved by material desire. Design service object is desire of human beings in the era of traditional 1 anthropocentrism values. However, fight and struggle for meeting endless desire provide human 
nature with chains, thereby leading to sadness and no freedom of human beings. It means that new Chinese architecture should not become exclusive product for a few people, desire object and luxury pronoun. It should be open to most people, and people can be integrated into culture, tradition and nature during living and use process. People can feel comfortable, unrestrained and free.

\section{New Chinese architecture and traditional culture}

Any one modern and contemporary culture can not be separated from historical tradition of the nation. Cultural identity is located at the higher level in Maslow's human demand theory. New Chinese architecture provides such an opportunity and reminds people to trace own cultural origin. Psychology and thinking modes of Chinese people are deeply shaped by Confucianism as traditional culture mainstream from the perspective of history. Richer levels in characters of Chinese people are also created by Taoist and Buddhist culture with long history. Such historic, national and regional culture link should be revealed by the new Chinese architecture, thereby enhancing people's cognition, understanding and memory on traditional value. A kind of group identity and belonging sense can be provided. It is essentially a part of human freedom.

\section{New Chinese architecture and modern-contemporary culture}

Any architecture must face actual demand of actual life in some era. Since traditional architecture is a product under political, culture, economic and technical conditions at a specific historical era. New Chinese regional architecture also should be directed to modern and contemporary culture in China. Its function and form should serve demand and aesthetics of modern people. Its structure and technology should not exclude the most advanced modern technology and means. Therefore, the succession of traditional architecture should not be constrained by old shape, style and practice. Spirit and artistic conception of traditional culture should be deeply understood and mastered. All possible techniques and means in modern and contemporary eras should be fully utilized for expression.

\section{Basic concept of new Chinese architecture design under ecological perspective}

Harmony, freedom and sustainability are basic concepts of new Chinese architectural design in ecological civilization perspective. Human beings, nature and culture should be integrated in new Chinese architecture design. History, present and future should be associated together for realizing actual comfortable house of human beings all over the world.

\section{Culture exploration of new Chinese architecture design basic principles under the perspective of ecological civilization}

New Chinese architecture should follow the principle of respect, protection and communication in design creation based on ecological concept.

\section{Respect principle}

Respect for human beings. New Chinese architecture design should follow the design principle of 'humanization' since libration of human beings is the final direction of ecological civilization. Ancient Chinese traditional Confucian culture focuses on ethics and etiquette. Architecture is not regarded as a noble art form. However, it appears as a tool for meeting basic living functions, and symbol carrier for embodying social hierarchy and identity difference. Architecture is limited by era. Individual life quality of human beings is not fully considered. For example, behaviors and demand of human beings are comprehensively analyzed in details from the perspective of environmental psychology and ergonomics theory. People should study how to pay equal attention to privacy and publicity, improve lighting, and create more appropriate measure in Chinese style space, and how to fit dimension of human beings by indoor furniture, etc.

Respect for human beings also means that new Chinese architecture design should respect true feelings of human beings in modern society. It is determined that new Chinese architecture significance lies in adding a beautiful option for comfortable house of human beings according to pluralism and openness of modern society. However, it should not be misled as an inevitable direction of Chinese building development in the future. Therefore, new Chinese architecture projects 
should be suitably planned and constructed. If ancient style is discovered anywhere, and the real estate project regards "new Chinese style" as the stunt, people may be set in an untrue situation, thereby causing confusion, and weakening the identity sense and sense of belonging.

Respect for tradition. Every culture and every tradition represent a unique wisdom of survival. Ecological ethics have key viewpoints of respect for individual culture unique value and advocating harmonious coexistence between different cultures. Design of new Chinese architecture also should inherit the excellent factors in Chinese traditional culture, which should be carried forward.

There are many cultures in human history, which adopt a negative attitude on real life. Value of life is emphasized in Confucian culture as the mainstream of Chinese traditional culture. It advocates pursuit of earthly life goals and realization of individual ideals. Ancient Chinese design also shows an optimistic, positive, even romantic and warm tone as a result. For example, multiple pure color concatenations are popular in design of color configuration, and they are matched with temperature contrast, thereby leading to a loud, lively, happy and festive atmosphere. In addition, when ancient Chinese people suffered from life setbacks, they can naturally give up trouble, get rid of materialistic desire trouble, return back into individual world with free mind, and enjoy life purity and peace at ease under the influence of Taoist and Buddhist thoughts. Correspondingly, there is another system of colors in Chinese ancient design, which is completely different seemingly: the system is quiet, indifferent, simple and elegant, such as simple black, white and grey in ink painting and Hui style architecture.

In addition, the traditional Confucian culture emphasizes moderate attitude to life. Extremes should be avoided. It is reflected in the design field as the concepts of modesty and decency. For example, Ming-style furniture is concise, delicate, simple and elegant. It is a model of 'elegance' advocated by Confucius. The ancient Chinese Confucian culture also pays attention to ethical culture. Even the plants in gardens also have moral meanings, such as plum, orchid, bamboo and chrysanthemum. They are called "four gentlemen" in the flower due to their unique qualities. Other common plants, such as conifers, lotus, magnolia denudata, winter jasmine, crabapple, osmanthus, etc. also have their own good implied meanings. Moreover, space design in ancient China is also composed of gardens, patios and other symbolic elements. The traditional elements are inherited and carried forward for providing new Chinese architecture with distinct personality characteristics, rich cultural atmosphere, and higher style and quality.

Respect for nature. Ecological thought believes that the earth environment is destroyed because human beings wrongly understand nature as 'natural object'. Nature becomes warehouse of human resources and materials, which is randomly claimed and trampled. Human beings do not realize that nature's essence is actually the mysterious and great creation strength behind natural phenomenon, which is not known at present. Therefore, human beings can step out by restoring nature mystery again, and respect for nature. Laozi- the ancestor of Taoism in ancient China said that human follows land, land follows sky, sky follows Taoism, and Taoism follows nature more than two thousand years ago. Here, Tao refers to natural laws. People should act according to laws of nature rather than artificially fighting against it. New Chinese architecture also should learn from the essence of Taoism culture and ecological thought, and reflect respect for nature. Building should not intentionally create, but should 'avoid' according to the views of ontology. Therefore fact can naturally emerge. Namely, people can clearly show the original structure and features of the site through planning, design and construction, which can be strengthened. Creation of New Chinese architecture should be combined with the terrain, which should conform to the topography, thereby avoiding massive changes in the environment. Its layout, shape, material and so on should be combined with the environment.

\section{Protection principle}

Protection means no harm, which is reflected as conservation of resources, maintenance of ecosystem and harmonious coexistence of human beings and other species.

Mencius-the ancient Confucian thinker proposed resources protectionist viewpoint more than two thousand years ago. He believed that people's production activities should be moderate. Wood chopping and finishing can not use up natural resources. New Chinese architecture also should adopt 
the design principle of minimalism, thereby minimizing resources and energy consumption in the process of construction.

Modern ecological ethics believes that original "indigenous people" on a piece of land are not human beings but animals, birds, fish, insects and microorganisms with natural growth. Their survival space is squeezed due to invasion of human beings. The right to life is deprived. Therefore, the construction of new Chinese architecture not only should meet the needs of people, but also should take care of the life rights and interests of other species. For example, habitats should be provided for other species in construction (even tiny insects, seeds, etc.). Good environment is cultivated for forming a local community ecological circulation system through controlling temperature, humidity, drainage, etc., therefore the base of new Chinese architecture can become a paradise with harmonious coexistence of human beings and nature.

\section{Communication principle}

Ecological philosophy thinks that everything in the ecological cycle system is associated with each other, and they depend on each other and implement energy transformation and communication at any time. Communication among architecture, human beings and nature also should be focused for the construction of new Chinese architecture.

Communication between new Chinese architecture and human beings. The new Chinese architecture in the ecological perspective bears rich humanities, history, nature, and other information. The information can be understood and accepted by people only through proper expression form. China ancient architectural shape and decorative pattern are products of history and culture, which must have limitations of the times. When traditional symbols are used in new Chinese architecture, the symbols should be firstly placed under the perspective of modern science aesthetics and psychology, which can be inherited, transformed and innovated. For example, Gestalt psychology thinks that human visual perception has the tendency of convergence, simplification, and separation between figure and background. People like slightly incomplete "gestalt graphics" and so on. Modern cognitive psychology believes that beauty has relation with the complexity of the object. Form design should be contracted rather than simplification. Therefore, some complicated patterns in Qing dynasty decoration in ancient China do not accord with the modern aesthetic view, which should be simplified. Large-area white wall in Hui style architecture also should avoid drab feeling to human beings. It can be provided with richer level by tree shadow, climbing plants, moss etc.

Communication between new Chinese architecture and nature. Chinese traditional 'Feng Shui' theory holds that the basic element of everything in nature is Qi. Qi is continuously circulated between earth and heaven. Heaven, earth, human beings and objects are integrated. Creation of architecture also should be included in the operation in the best mode. Even site selection, construction start time, etc. should be carefully considered since unbeneficial results can be finally caused due to any interference on operation of Qi. It is consistent with the viewpoint of modern ecological theory-everything is interlinked and dependent. The construction of new Chinese architecture also should be included into natural and biology cycle in a best way. It means that the position, construction, etc. should be integrated with nature in the mode with the lowest damage. Day-lighting, ventilation, etc. should strive for the best benefits from nature by low attitude and passive technique. Recycled and renewable materials should be adopted for construction as much as possible. Itsuko Hasegawa- a Japanese architecture expert said that 'architecture is also a product of nature like human beings, it is originated from nature, and returned to the nature in the form of death and destroy, and it is a more far-reaching form of life'. In addition, since materials need to pass the information such as identity, grade, etc. in traditional Chinese architecture, they are always decorated by paint, painting, etc. original texture is covered, thereby blocking communication among architecture, human beings and nature to certain extent. These materials also can be opened by the new Chinese architecture, thereby showing the charm of natural color, and texture of materials. 


\section{Conclusion}

New Chinese architecture has the essence of humanity care in ecological perspective. Its value lies in integrating tradition, nature and humanity. An option is provided for realizing poetic habitation of human beings. Its design should follow the principles of respect, protection and communication, thereby realizing harmonious coexistence of human beings, architecture and environment. The concrete realization mode of new Chinese architecture also should be constantly explored and thought in current practice in ecological perspective, which can be concluded and summarized.

\section{References}

[1]Zhu Jin. Architectural design principles and methods. Shanghai: Donghua University Press, 2009.

[2] Wang Xueyong, Liu Haiyan. Interpretation of "new chinese" architectural style. Journal of Shandong Agricultural University(Natural Science Edition), Journal of Shandong Agricultural University(Natural Science Edition) 2013, 44(2).

[3] Zhu Ningning, Zhao Xiaodong. Innovation of the Styles of Chinese Architecture, Urbanism and Architecture, 2014, (35).

[4] Guo Quanmin, Liu Xue, Xiong Wei. Exploration and Practice of the New Chinese Architecture Style, Journal of Beijing Institute of Civil Engineering and Architecture, 2014, (3).

[5]Wang Fuping, Li Dexiang. Integrated Application of Green Technique to Eco-building Design. Architectural journal. 2007, (9).

[6] Yang Li. The Application of Ecological Technology Strategies in Norman Foster's Architectural Design Works. Building Science. 2012, 28(6).

[7 Liu Zhihong. An Exploration of Ecological Architecture Design of World Tourist Attraction. Hundred Schools In Arts, 2014, 30(3).

[8]Li Xiaojun, Chen Xiang. Sustainable Ecological Architecture Design. Architectural journal. 2001, (5).

[9]Chen Ying, Wang Huiming, Zhang Aimin, at el. Discussion and analysis on application of biological simulation technology in green building design. Architecture Technology, 2014, 45(4).

[10]Wang Haisong, Mo Hongzhi, Shen Bin. Study of the Integrated Design System for Eco-building. ARCHITECTURAL JOURNAL, 2007, (9). 